\title{
AS NARRATIVAS DE SI E AS TRAVESSIAS CONSTRUÍDAS NO PROCESSO DA COMPLEXIDADE DA FORMAÇÃO INICIAL
}

\author{
Silmara Bispo de Cristo Souza ${ }^{1}$ \\ Aurea da Silva Pereira ${ }^{2}$
}

\begin{abstract}
Resumo: Nesta pesquisa buscamos investigar a complexidade que envolve os processos formativos desde a formação inicial, com foco na investigação do Estágio Supervisionado. Partimos do pressuposto de que o modo como se desenvolvem os estágios, na formação inicial do (a) futuro (a) professor (a), tem fundamental importância no processo de construção da identidade docente, uma vez se efetivam como os momentos de vivenciar a profissão, de se deparar com a desafiante necessidade de articular (de forma reflexiva) as teorias estudadas com a prática em sala de aula e de perceber as lacunas deixadas pelo processo de formação. Utilizamos a perspectiva autobiográfica a partir da análise de entrevistas narrativas realizadas com os colaboradores dessa pesquisa: três estudantes (duas alunas e um aluno) do Curso de Letras da UNEB, Campus II e a professora de estágio destes (as). Aos alunos (as), participantes da pesquisa, foram dados nomes fictícios de acordo com a característica mais demarcada nas narrativas: "Determinação", "Resiliência" e "Dedicação"; a professora de estágio permitiu a divulgação do seu nome - Professora Ana Regina. Apropriamos-nos das concepções apresentadas por eles (as) e dialogamos com abordagens teóricas suscitando a problematização de questões como a não superação da racionalidade técnica nos cursos de formação, a desafiante relação teoria-prática, a responsabilidade do professor (a) de estágio nesse processo inicial de formação e o lugar da reflexão no Estágio Supervisionado.
\end{abstract}

Palavras-chave: Estágio Supervisionado. Formação Inicial. Narrativa autobiográfica.

\footnotetext{
${ }^{1}$ Licenciada no curso de Letras com Habilitação em Língua Portuguesa e Literaturas pela Universidade do Estado da Bahia (2016). Atuou como pesquisadora bolsista no projeto de iniciação científica intitulado como Masculinidades e masculinos efeminados: os desafios para os estudos da identidade sexual na literatura baiana, com financiamento da FAPESB. Mestranda do Programa em Pós-graduação em Crítica Cultural, na linha 02 de pesquisa.

2 Possui graduação em Letras Vernáculas pela Universidade do Estado da Bahia (1996), Especialista em Linguística aplicada ao ensino da Língua Portuguesa pela Universidade Estadual de Feira de Santana (1998), Mestre em Educação e Contemporaneidade pela Universidade do Estado da Bahia (2008) e Doutora em Educação e Contemporaneidade pela Universidade do Estado da Bahia (2014). Professora Adjunto do Colegiado de Letras, Departamento de Educação - Campus II /UNEB. Atualmente atua na linha de pesquisa 2- Letramento, identidades e formação de educadores do Programa de Pós-graduação em Crítica Cultural (UNEB) . Faz parte dos seguintes grupos de pesquisa: GRAFHO -Grupo de Pesquisa Autobiografia Formação História Oral; GEREL - Grupo de Estudos em Resiliência, Educação e Linguagens; e, GEPHEG - Grupo de estudos e pesquisas em história, educação e gênero.
} 


\title{
NARRATIVES OF IS AND CROSSINGS BUILT IN THE COMPLEXITY PROCESS OF INITIAL TRAINING
}

\begin{abstract}
In this research we seek to investigate the complexity that involves the training processes from the initial formation, focusing on the investigation of the Supervised Internship. We start from the assumption that the way in which the stages are developed, in the initial formation of the future teacher, is of fundamental importance in the process of constructing the teaching identity, once they become effective as the moments of experiencing the profession, to face the challenging need to articulate (in a reflexive way) the theories studied with the practice in the classroom and to perceive the gaps left by the training process. We used the autobiographical perspective from the analysis of narrative interviews conducted with the collaborators of this research: three students (two students and one student) from the UNEB Literature Course, Campus II and their trainee teacher. The students, who participated in the research, were given fictitious names according to the characteristic most marked in the narratives: "Determination", "Resilience" and "Dedication"; the trainee teacher allowed the release of her name - Professor Ana Regina. We approve of the conceptions presented by them and dialogue with theoretical approaches, raising the questioning of issues such as not overcoming technical rationality in training courses, the challenging theorypractice relationship, the responsibility of the trainee teacher in this initial training process and the place of reflection in the Supervised Internship.
\end{abstract}

Keywords: Supervised internship. Initial formation. Autobiographical narrative.

\section{Introdução}

A formação de professores vivenciou diversos momentos de transformações, principalmente na organização e nas políticas públicas, mas sempre prevaleceu a valorização de modelos centrados na racionalidade técnica. Ao longo da história dos cursos de formação, a discussão acerca da dicotomia entre saberes teóricos e saberes práticos, a supervalorização da dimensão científica, em detrimento do pessoal, do subjetivo, sempre foi algo recorrente e, ainda hoje, constituem problemáticas que circundam o cenário da formação inicial. Dentre todas essas questões apontadas, o processo de articulação entre teoria e prática, muito preconizado pelas diretrizes educacionais nacionais, é um dos grandes pontos de conflitos nos cursos de 
licenciaturas, principalmente quando o trabalho com a prática é atribuído exclusivamente aos componentes de Estágio.

A necessidade de repensar a formação inicial de professores se associa ao fato de que o trabalho dos docentes em atuação tem sido questionado por não alcançar um processo de aprendizagem significativo e de qualidade. Apesar de existirem algumas exceções, há um predomínio de práticas pedagógicas tradicionais, conteudistas e reprodutivistas. Esse ensino conservador, ainda hegemônico no contexto escolar, é resultado, muitas vezes, do próprio processo de formação desses educadores.

Diante da realidade da escola atual faz-se necessária uma formação que considere o professor como um intelectual crítico-reflexivo (PIMENTA, 2008). No atual contexto educacional não cabe mais práticas técnicas e tradicionais, é preciso superar esses modelos a partir de uma nova epistemologia da formação docente, pautada em uma prática educativa contextualizada, crítica e transformadora. Para isso, as mudanças devem se iniciar no próprio processo de formação inicial.

Assim sendo, a formação inicial deve ser pensada como um processo de autoformação e autotransformação do sujeito que tem a capacidade de provocar aprendizagens em diferentes domínios da existência, a partir do seu modo de ser, estar sentir, refletir e agir. A experiência pessoal de cada sujeito é única, e, portanto, os resultados do processo formativo dependem, diretamente, do modo como vivenciou e vivenciam os seus percursos formativos. Nesse sentido, os dispositivos utilizados para possibilitar o desenvolvimento pessoal e profissional tornam-se um fator determinante para que os licenciandos (as) assumam os seus papéis como sujeitos da sua formação e de sua prática docente.

Ao entendermos a complexidade que envolve os processos formativos, o contexto e espaço-tempo dessa investigação se voltou para a formação inicial na especificidade do estágio supervisionado. Adotamos a pesquisa (auto)biográfica como aporte teórico-metodológico, tendo como foco central de análise a formação dimensionada pela reflexão sobre a experiência. Compreendemos que as narrativas de formação se efetivam como um terreno fértil que possibilita superar as dimensões técnicas e instrumentais da formação inicial e do estágio, e por isso, o movimento da investigaçãoformação desse estudo se configurou a partir do processo de 
(auto)conhecimento e (auto)formação apresentados pelos sujeitos em narrativas produzidas no Estágio Supervisionado.

Assim, nessa discussão trazemos problemáticas que perpassam a formação inicial e o lugar do Estágio Supervisionado nesse processo. Todas essas questões são apresentadas a partir dos depoimentos dos sujeitos dessa pesquisa:três estudantes (duas alunas e um aluno) do Curso de Letras da UNEB, Campus II e a professora de estágio dos sujeitos da pesquisa. Aos alunos (as), participantes da pesquisa, foram dados nomes fictícios de acordo com a característica mais demarcada nas narrativas: "Determinação", "Resiliência" e "Dedicação"; a professora de estágio permitiu a divulgação do seu nome - Professora Ana Regina. Apropriamo-nos das concepções apresentadas por eles (as) e dialogamos com abordagens teóricas suscitando a problematização de questões como a não superação da racionalidade técnica nos cursos de formação, a desafiante relação teoria-prática, a responsabilidade do professor (a) de estágio nesse processo inicial de formação e o lugar da reflexão no Estágio Supervisionado.

Utilizamos a perspectiva autobiográfica a partir da análise de entrevistas narrativas realizadas com os colaboradores dessa pesquisa. Através dessa escrita eles(as)narram, descrevem, refletem e reconstroem as experiências de vida e de formação, remontando aspectos que contribuem para o seus respectivos processos formativos.

Nesse estudo, compartilhamos uma concepção de estágio que aponta para uma perspectiva crítico-reflexiva, visando à percepção da organização do ensino e de suas especificidades, tendo em vista a possibilidade de criar alternativas e condições para um processo de aprendizagem significativo e bem articulado. Essa concepção crítico-reflexiva foi possibilitada pelo modo como a professora de estágio pensa a formação para a docência, a partir de um paradigma que reconhece a subjetividade dentro do processo formativo, possibilitando que os estudantes sejam sujeitos da sua própria formação. Para isso, as narrativas autobiográficas tornam-se elementos cruciais para o processo de (re)conhecimento de si e para estabelecer a reflexão acerca da complexidade da docência.

A partir dessa concepção de estágio a formação inicial de professores expressa oportunidades de construção de diferenciados de saberes constituidores da identidade docente, pois permite a possibilidade de articulação e problematização crítica dos saberes teóricos e pedagógicoscomo 
exercício orientado e reflexivo da docência. Nesse sentido, o estar professor possibilita que identidades docentes sejam construídas e ressignificadas no entrecruzamento de diferentes saberes e trajetórias que se iniciam na infância, perpassa a escolarização, até chegar à formação universitária e sua práxis profissional.

\section{Identidades que se cruzam no processo de formação inicial: Do formador ao futuro professor}

Sendo o professor responsável pela formação humana e científica, ele necessita estar em contato permanente com estudos, pesquisas e experiências formativas. A construção da identidade docente é um processo contínuo e inacabado, uma vez que necessita de uma constante revisão das suas práticas educativas, como afirma Pimenta (2005, p. 18):

[...] constrói-se também pelo significado que cada professor, enquanto ator e autor confere à atividade docente em seu cotidiano, em seu modo de situar-se no mundo com sua história de vida, em suas representações, em seus saberes, em suas angústias e anseios, no sentido que tem em sua vida o ser professor.

A formação inicial é um dos importantes espaços para a percepção desse processo, uma vez que é possível perceber o professor que está sendo formado e a partir de quais referências e concepções essa formação tem se estabelecido; quais os significados que cada futuro (a) professor (a) tem atribuído a sua formação e como eles (as) estão sendo movidos para serem os autores e atores de seus processos formativos. Assim, torna-se interessante investigar esse processo a partir do olhar dos estudantes do Curso de Letras e da professora de Estágio.

A entrevista narrativa realizada com a professora de estágio comprova a permanência da adoção da perspectiva de formação técnica por parte de alguns professores. Em relação a essas posturas, a professora de estágio se posiciona de maneira contrária quando propõe uma prática reflexiva e crítica negativamente a visão conteudista. Quando defende uma postura formativa que perpassa pela reflexão, a professora salienta que:

Essa postura se distancia da visão conteudista e quantitativa que sustenta a prática de professores (as) 
que acreditam que "quanto mais textos e livros os/as estudantes leiam, melhor formadoseles (as) estarão". (Professora Ana Regina)

O discurso da professora é confirmado pelo posicionamento de Resiliência, Dedicação e Determinação quando refletem sobre o formato do curso de Letras no que concerne às práticas dos seus professores desde o início do curso:

No curso vimos muitas teorias que muitas vezes não tem relação com o contexto da sala de aula. Durante todo o curso apenas um professor trabalhou a literatura voltada para a sala de aula. Lembro que quando ele trabalhava alguns poemas, mostrava como deveríamos utilizá-lo na aula. [...] Mas os outros (até chegar ao componente de estágio), em sua maioria, nos enchiam de textos e mais textos e, muitas vezes, nós graduandos, nos questionávamos se tudo aquilo teria relação com a sala de aula. (Resiliência)

Muitos professores só querem dar sua aula e voltar para casa. Já estão com suas disciplinas formadinhas. Cada um já sabe o que vai dar no ano seguinte. (Dedicação)

Muitas vezes nos questionamos o "porquê" de algumas disciplinas em um curso de Letras, o "porquê" de algumas teorias que nos são passadas, o "porquê" de tão pouca prática em um curso de licenciatura. Muitas vezes nos percebemos comoum depósito de teorias que desarticuladas do contexto escolar não nos faz sentido. (Determinação)

Esses depoimentos nos fazem retomar aos fundamentos da racionalidade técnica, pois enfatizam o treinamento de habilidades comportamentais e são organizados a partir da mera transmissão de conteúdos ditos científicos, estes entendidos como suficientes no processo de formação de docentes. Desta forma, a partir desses relatos, os professores em formação estão sendo direcionados (por alguns formadores) para serem concebidos como técnicos que, de forma objetiva, devem pôr em prática os conhecimentos científicos a partir da aplicação rigorosa de princípios, técnicas e conhecimentos gerais. Ainda que prevaleça essa formação voltada para uma perspectiva técnica, os sujeitos dessa pesquisa se apropriam de uma postura reflexiva acerca de sua formação e, ao invés de serem mobilizados 
para um processo formativo técnico, revelam uma rejeição a esse modelo, desencadeando desdobramentos significativos para a formação de sua identidade docente.

É lamentável perceber que até mesmo no processo de formação inicial de professores ainda existam formadores apegados a um formato tecnicista. Os três depoimentos deixam claro o comodismo desses docentes e a prática viciada e desvinculada de reflexão, como podemos observar nos seguintes excertos: "nos enchiam de textos e mais textos"; “cada um já sabe o que vai dar no ano seguinte”;“nos percebemos como um depósito de teorias que desarticulados do contexto escolar não nos faz sentido". Os excertoscomprovam que a formação de professores têm se estabelecido a partir de uma perspectiva técnica.

Nesse sentido, uma concepção que por vezes é criticada dentro da academia acaba sendo reproduzida pelos próprios formadores. As práticas pedagógicas dos professores universitários refletem a ambiguidade e as contradições de sua profissão e da própria universidade; além disso, estas ações revelam que a prática educacional universitária continua, em alguns momentos, enraizada na concepção bancária da educação.

Na concepção de Freire (1970), a educação bancáriaé uma metáfora de uma vertente educacional não emancipadora que apresenta uma educação, na qual os professores assumem o papel de um mero narrador de conteúdo e o aluno passivamente ouve. Nesse sentido, "a educação bancária" se efetiva como um instrumento legitimador, de ordem opressiva, visto que inviabiliza o desenvolvimento de um pensamento autônomo e a construção de uma consciência crítica.

Os docentes universitários são os responsáveis diretos pela criação de possibilidades que proporcionem a produção de conhecimento dentro de um contexto autêntico, crítico e reflexivo, propiciando assim a renovação das práticas de ensino existentes. Segundo Costa (2008),

[...] os estabelecimentos de ensino superior, em conjunto com seus docentes, precisam abandonar a postura tradicional, aulista e expositiva de repassar ideias, buscar renovar as metodologias que estão ultrapassadas e, por fim, apropriar-se da perspectiva educacional moderna, associada com a realidade atual, da sociedade e do conhecimento (COSTA, 2008, p. 45). 
No cenário de formação inicial de professores um dos aspectos cruciais no processo formativo destes futuros profissionais é o diálogo significativo entre universidade e contexto escolar. De que adianta a produção de conhecimento no campo acadêmico, se esse conhecimento não for integrado, de maneira crítica e reflexiva, aos espaços pedagógicos?

O desenvolvimento pessoal e profissional de um professor em formação inicial se efetiva como um processo complexo que é determinado pelo modo como ele se posiciona em relação a múltiplas e, por vezes, contraditórias situações. Para tanto, contribuem também múltiplos e, por vezes, contraditórios significados, pontos de vista, valores morais, crenças expressos pelos discursos elaborados por vários interlocutores em diferentes contextos criados nas instituições sociais, nos vários campos científicos, nas legislações.Dessa forma, o processo de constituição de identidades docentes é uma construção marcada por uma multiplicidade de discursos e agentes sociais, e por isso, pensar o modo como se dá processo de constituição de identidades docentes de futuros professores passa, antes de tudo, pelo entendimento das ações dos formadores, pelo modo como estes têm servido de representação da identidade docente, pelo modo como estes estão lidando com os seus próprios processos de constituição identitária.

Dentro dessa esteira de discussão, Behrens (1996, p. 103-111) ressalta uma abordagem interessante quando aponta que a maior dificuldade percebida no processo de formação docente é o fato de a própria comunidade acadêmica encarar o professor como um profissional acabado. Os relatos dos colaboradores mostram que se torna imprescindível desencadear perspectivas teóricas, metodológicas e práticas que incitem à construção de um novo papel do professor dentro da comunidade acadêmica e na sociedade.

Em relação ao processo de constituição da identidade profissional, Nóvoa (1992) relata que a identidade não é um dado adquirido, uma propriedade ou um produto. Para o autor, “a identidade é um lugar de conflitos, é um espaço de construção de maneiras de ser e de estar na profissão"(p. 16), por isso, a forma adequada de referir-se a ela é como "processo identitário, realçando a mescla dinâmica que caracteriza a maneira como cada um se sente e se diz professor" (p. 16).

A construção de identidades passa sempre por um processo complexo graças ao qual cada um se apropria do sentido da sua história pessoal e profissional. É um 

identidades, para acomodar inovações, para assimilar mudanças. (NÓVOA, 1992, p. 16)

Partindo dessa perspectiva, fica evidente que a identidade do professor deve estar em constante transformação, deve ser (re)construída no cotidiano a partir da revisão de sua própria prática, proporcionando assim, espaço para as inovações, para um novo fazer ressignificado diante das necessidades do contexto no qual ele se insere.

A busca pela compreensão do modo como as identidades dos professores universitários têm se manifestado em suas interações em sala de aula torna-se imprescindível no processo de formação inicial e continuada. Determinadas posições identitárias se movimentam a partir das relações com outras posições, assim como os valores, discursos e crenças relativas a cada uma. Assim sendo, o processo de constituição de identidades docentes aparece articulado à percepção das representações de outras identidades. Isto é, a construção das identidades profissionais desses colaboradores está diretamente relacionada aos modelos das identidades profissionais de seus formadores. É um processo dialógico, existe sempre uma relação com o(s) outro(s), e, por isso, é mais que um acontecimento social e coletivo.

Nesta perspectiva, Silva e Matencio (2005) ressaltam que embora o sujeito seja singular (entendendo os princípios biológicos), está circunscrito no seu tempo e espaço, por isso, é produto e produtor das condições de sua emergência. Sob esse ângulo, os seus posicionamentos identitários seriam resultados de suas diferenças ou semelhanças em relação ao outro. Assim, [...] a construção de posicionamentos identitários emerge de movimentos baseados tanto na diferença como na similitude do sujeito em relação ao outro (eu/outro; eu/espelhamento do outro).

$\mathrm{Na}$ relação aqui estabelecida entre os sujeitos da pesquisa (graduandos, futuros professores) e os seus formadores (professores universitários) conseguimos perceber esses movimentos, ora de distanciamento, ora de espelhamento e valorização da prática, pois, assim como os colaboradores chamam a atenção para ações que não tem dado sentido aos seus processos formativos, eles(as) também retomam os professores que tiveram ações críticas e reflexivas. Os futuros professores revelam as representações significantes, ao mesmo tempo em que demonstram, através das críticas imprimidas em seus discursos, os 
professores quequerem ser, as ações que embasam a formação dos seus perfis profissionais e os traços identitários que interferem positivamente em suas construções enquanto sujeitos e futuros profissionais.

Tive um professor [...] que se preocupou em mostrar como a literatura deve ser trabalhada em sala de aula. Nós alunos, ficamos maravilhados com a forma que ele trabalhava, a simplicidade que ele "debulhava" um poema mostrando o significado de cada palavra, o sentido que tinha cada verso, enfim! (Resiliência)

Tive um professor que pensa num curso totalmente voltado para a sala de aula, desde o primeiro semestre. Isso é muito importante em um curso de licenciatura [...] Mas tem muita resistência de alguns professores que não querem sair do comodismo. (Dedicação)

Somente professora 'nome da professora' sempre fez questão de trabalhar o conteúdo dela fazendo um link com a questão pedagógica, como poderia ser levado para a sala de aula, fora isso, recordo que os outros se centraram em suas áreas específicas. (Determinação)

Pensar, refletir e analisar os posicionamentos dos seus formadores remete a compreender o próprio processo de construção da identidade, pois este não é solitário, faz-se em contextos, em interações, com trocas, aprendizagens, observações e reflexões.

Propor a reformulação do plano do curso, trabalhar textos literários levando-os para a realidade da sala de aula e fazer um "link" de sua disciplina com a questão pedagógica foram ações citadas pelos colaboradores que não deveriam mais se efetivarem como lacunas no processo de formação de professores. O projeto de curso deve ser pensado de maneira coerente, atendendo as necessidades pertinentes à carreira desses futuros profissionais, e para isso, é de fundamental importância o interesse e o envolvimento desses formadores no que concerne à preparação pedagógica, e não só a preocupação com a abordagem teórica de suas áreas específicas.

Professores que formam professores necessitam compreender que existem novos desafios a serem superados, entre os quais se encontra a necessidade de identificar o colapso das certezas absolutas e da docência orientada por paradigmas tradicionais, individualistas e centralistas. 
Para alcançar as competências exigidas para o professor do ensino superior na atualidade, é necessário falar em um processo inicial como um espaço de tomadas de decisões formativas (ZABALZA, 2004) que permita uma formação mais ampla e completa, englobando conhecimentos em procedimentos didáticos pedagógicos, desenvolvimento pessoal, cultural, acadêmico e profissional, ampliação da sensibilidade dos valores e atitudes de maneira que o docente possa relacionar-se melhor consigo mesmo e com os outros e, por fim, a formação deve comportar a troca, a mudança intermitente permitindo a ampliação das experiências.

Essa formação perpassa por reflexão e inovações contribui com a professora-formadora, destacada nesse estudo. A professora Ana Regina foi também citada pelos colaboradores, porém, não aparece nenhuma menção a ela nos depoimentos anteriores por se tratar da formadora de estágio. Quando falavam da articulação teoria e prática ou quando eram questionados sobre a preocupação com a preparação pedagógica do curso, os sujeitos sempre ressaltavam a professora de estágio como a promotora desses processos, como será apresentada na próxima seção. Nesse sentido, é interessante compreender o modo como Ana Regina concebe a sua responsabilidade dentro de um curso de formação:

Bem, quando afirmo que concebo a educação como transformação mediante si mesmo/a, os/as outros/as e o mundo e como autoformação, formação como me constituí o que sou e o que gostaria de ser, o que proponho como leituras, como fundamentos para os (as) estudantes, deverão ter sentido para eles (as); deverão ser leituras que sustentem suas práticas e os(as) façam pensar se aquilo que irão fazer em sala de aula, é condizente com aquilo que pensam. Tal postura reflexiva anula a dicotomia teoria/prática, uma vez que aquilo que estudo em um curso de formação de professores, tem sentido porque está associado diretamente ao fazer e ao viver, tem sentido para a minha existência humana e não apenas docente, torna-me um(a) profissional melhor porque me torna uma pessoa melhor. São leituras que me trazem não apenas conhecimento, mas, sobretudo, sabedoria, como afirma Larrossa, porque edificam e transpassam; são leituras que me tocam, que ficam. (Professora Ana Regina)

É importante perceber no depoimento da professora de estágio um posicionamento reflexivo, uma identidade aberta a um processo constante de 
modificações, no qual a mesma pensa a sua própria formação refletindo criticamente o resultado de suas ações sobre a formação do outro.

Dessa forma, percebemos a reflexão de uma prática aliada à teoria, uma vez que se impõe a necessidade de uma atividade em que os futuros profissionais mobilizem os conhecimentos adquiridos em meio à realidade da sala de aula. Barreiro e Gebran (2006, p. 21) acrescentam que:

\begin{abstract}
Isso significa, pois que a formação inicial e o estágio devem pautar-se pela investigação da realidade, por uma prática intencional, de modo que as ações sejam marcadas por processos reflexivos entre os professoresformadores e os futuros professores, ao examinarem, questionarem e avaliarem criticamente o seu fazer, o seu pensar e a sua prática.
\end{abstract}

Esse modo reflexivo em que tem se dado a relação de Ana Regina com osfuturos(as) professores(as) torna-se interessante a medida em que percebemos que muitos graduandos de licenciaturas chegam ao componente de estágio perdidos por não conseguirem, até o momento, encontrar sentido no seu processo formativo, o que acarreta, muitas vezes, a crise de identidade.

\title{
Concepções de estágio e a relação teoria e prática
}

O estágio se configura como uma das etapas mais importantes do processo de formação inicial de professores. É o momento da reelaboração e ressignificação dos saberes teóricos e pessoais construídos ao longo da formação específica e de vida e também dos saberes profissionais.

Discutir acerca das concepções de Estágio Supervisionado tem sido uma problemática que tem despertado interesse em diversos pesquisadores da área educacional. Ao suscitar essa discussão, é pertinente invocar a definição do estágio a partir das abordagens de Pimenta e Lima (2011), ondeeste é definido como:

[...] campo de conhecimento e eixo curricular central nos cursos de formação de professores que possibilita que sejam trabalhados aspectos indispensáveis à construção da identidade, dos saberes e das posturas específicas ao exercício profissional docente. (PIMENTA; LIMA, 2011, p. 61) 
Dessa forma, entendemos que o estágio deve ocupar um lugar de destaque dentro dos cursos de formação de professores, uma vez que, para muitos graduandos, o único contato de acesso à sala de aulaaconteceu na condição de alunos e no momento do estágio. Assim sendo, é a sala de aula o lugar da formação, é nesse espaço que o estagiário estabelece um contato direto com o seu ambiente de atuação pedagógica, sendo mobilizado a se perceber como professor. Nesse sentido, as disciplinas de estágios tornam-se essenciais para a aproximação dos futuros professorescom as diferentes possibilidades teórico-práticas, possibilitando, ao longo desse processo, a constituição da identidade profissional. Assim, o planejamento dessas disciplinas precisam possibilitar espaços de diálogo, trocas, descobertas e reflexão.

Portanto, é no momento dos estágios que os futuros professores devem refletir, discutir e problematizar questões sobre a escola, a sala de aula, o fazer pedagógico, os conteúdos que serão ensinados. Configura-se então como um espaço privilegiado de aprendizagem da profissão docente e de possibilidade de construção da identidade profissional.

Nessa perspectiva, Pimenta e Lima (2011) ressaltam que o estágio pode se evidenciar como um campo de pesquisa e investigação, uma vez que este não se reduza à atividade prática instrumental e possibilite a construção da identidade docente. Ainda de acordo com as autoras, entendemos que o objetivo do estágio é proporcionar a integração da formação do futuro professor, compreendendo a escola e o seu campo de atuação como objeto de reflexão, análise e investigação, ao considerar indispensável a relação de articulação dessa experiência formadora com os conhecimentos discutidos nas disciplinas do curso de licenciatura. Sendo assim, o estágio possibilita a aproximação dos futuros professores da realidade que atuarão, e por meio da análise critica apoiada na teoria, eles(as) se apropriam dessa realidade com maior autonomia e sensação de pertencimento.

No entanto, as possibilidades e potencialidades dos estágios supervisionados tornam-se inacessíveis quando os estagiários vão para a escola apenas para observar as aulas (no estágio de observação, por exemplo) ou somente para a transmissão de conteúdos (estágio de regência), sem a oportunidade de discutir, problematizar e refletir esses acontecimentos a fim de compreendê-los dentro das peculiaridades de sua futura profissão. 
As bases legais que regem a formação inicial de professores apresentam pressupostos que se aproximam de um enfoque reflexivo que se apresente desde o início da formação. Nesse contexto, torna-se relevante retomarmos o Art. 12 da Resolução CNE/CP1, já citado anteriormente, para contextualizá-lo dentro da situação específica (Estágio no Curso de Letras do Campus da UNEB investigado):

Art.12. Os cursos de formação de professores em nível superior terão a sua duração definida pelo Conselho Pleno, em parecer e resolução específica sobre sua carga horária.

§ 1ㅇ A prática, na matriz curricular, não poderá ficar reduzida a um espaço isolado, que a restrinja ao estágio, desarticulando do restante do curso.

$\S 2$ 2o A prática deverá estar presente desde o início do curso e permear toda a formação do professor $\S 3$ o No interior das áreas ou das disciplinas que constituírem os componentes curriculares de formação, e não apenas nas disciplinas pedagógicas, todas terão a sua dimensão prática.

Como previsto no Art. 12, a prática deve estar presente em todo o processo formativo, articulando-se, de maneira reflexiva, com as teorias das disciplinas específicas. No entanto, no contexto analisado não foi possível perceber a efetivação desse discurso, uma vez que os sujeitos da pesquisa trazem depoimentos totalmente contrários a essa concepção de formação:

Cada professor se pauta apenas em seu componente e realmente o professor de estágio fica sobrecarregado: preocupado com a teoria, ajudar na elaboração dos planos e acompanhar a prática dos discentes. (Determinação)

A formação pedagógica acaba ficando muito a cargo do professor de prática pedagógica e, principalmente, do professor de estágio. (Dedicação)

O aluno só vai ter vivência em sala de aula no final do curso. (Resiliência)

Nos depoimentos, é unânime a concepção de que teoria e prática encontram-se desvinculadas no processo de formação inicial. Isso se dá pelo fato de esse binômio (teoria e prática) estar atrelado a uma relação caracterizada por uma trajetória histórica que se volta para uma perspectiva 
dicotômica, o que afeta negativamente o efetivo desenvolvimento dos saberes docentes e de uma identidade profissional crítica e reflexiva. De acordo com Candau e Lelis (1995) essa desarticulação decorre, sobretudo, da assunção de uma visão dicotômica da relação entre teoria e prática, ou seja, do entendimento de que teoria e prática são pólos distintos e separados. Desse sistema histórico demarcado pela instrumentalização do saber resulta a formação desses formadores (professores universitários), uma vez que essa dicotomia se faz presente nos contextos formativos há décadas:

\begin{abstract}
Verificamos que a dicotomia entre teoria e prática já aparece nos anos 30, quando havia uma estrutura curricular que estabelecia uma hierarquia entre conteúdo e metodologia. Nos anos 60, com a Reforma Universitária, reforça-se ainda mais a separação entre as disciplinas específicas e as pedagógicas. O modelo da racionalidade técnica, nos anos 70, privilegia a formação teórica e a prática é vista como aplicação da teoria. Nos anos 80, o problema da dicotomia entre a teoria e a prática foi muito discutido devido às influências das reflexões levantadas por Vásquez. Em 1990, embora passe a ser enunciada a relação teoria-prática como um eixo articulador do currículo, e em 1996, no art. 61 da LDB, seja prevista a "associação entre teoria e prática", os problemas da dicotomia permanecem os mesmos (PEREIRA, 2005, p. 87).
\end{abstract}

Assim, percebemos que essa desarticulação entre teoria e prática não é algo novo nos cursos de formação e não nos parece ser algo a ser superado em um curto período de tempo, uma vez que ainda percebemos, de maneira muito presente, o predomínio de estruturas curriculares e práticas formativas que fortalecem a dissociação entre conteúdos e metodologias, disciplinas específicas e disciplinas pedagógicas. Dedicação e determinação fazem uma ressalva importante no que se refere ao funcionamento da disciplina de Prática Pedagógica (entendida, no currículo do curso, como um componente que preconiza também a discussão da teoria e prática):

Pra que uma disciplina com uma carga horária tão grande como Prática Pedagógica se a gente não tem contato com a sala de aula? Então não é Prática Pedagógica, é Teoria Pedagógica. (Dedicação)

Na minha opinião, e essa também é uma crítica de outras pessoas, não deveria existir uma disciplina chamada de 


\begin{abstract}
"Prática Pedagógica"; eu penso que as disciplinas deveriam ser ofertadas e dentro dessas disciplinas já houvesse uma forma de lidar com o pedagógico. A gente está sendo formado para ser professor de Língua Portuguesa, então a pedagogia que a gente precisa aprender é a pedagogia de Língua Portuguesa: Como trabalhar com a lingüística? Como trabalhar com a literatura? Como trabalhar com a oralidade? Eu acho que toda a disciplina já deveria trabalhar com isso, por exemplo, o componente de Diversidade Linguística já deveria ter uma parte destinada a pensar como aquilo poderia ser levado para a sala; "Teoria da Literatura", dentro dessa disciplina já deveria existir uma carga horária destina a lidar com esse saber teórico e a prática. É como se nossos professores não fossem professores de Língua Portuguesa, o professor de Literatura parece ser só de Literatura, o professor de Linguística parece ser só de Linguística... (Determinação).
\end{abstract}

Percebemos que no discurso de Dedicação há uma crítica à Prática Pedagógica como componente curricular por não ter contribuído com sua formação.Como se falar/pensar a prática pedagógica sem vivenciar o contexto da sala de aula? O primeiro depoimento traz à tona uma reflexão muito interessante à medida que percebemos que um componente que se refere à prática tem se constituído de forma teórica. Odepoimento de Determinação, reforça a segregação de áreas e a desvalorização da articulação entre o pensar e o fazer e apresenta intervenções próprias acerca do modo como ele acredita que a formação se tornaria mais contextualizada e significativa. Toda essa problemática que se instaura nesse processo inicial tem acarretado uma responsabilidade muito grande para o componente de Estágio Supervisionado e, consequentemente, para a professora que ministra o componente curricular. Desta forma, somente a partir dos quatro últimos semestres, os sujeitos dessa pesquisa começaram a ter o entendimento de que teoria e prática não são pólos distintos e isolados, mas, ainda assim, ressaltam dificuldades percebidas quando se tem uma responsabilidade tão grande entregue a uma única professora:

Cada professor deveria lecionar seu componente e relacionar com o ambiente escolar, mas durante todo o curso não há esse interesse. 0 professor de estágio trabalha sozinho como se o estágio fosse outro curso e não outro componente.(Resiliência). 
A fragmentação existe e eu creio que isso nos prejudique. Nem sempre o professor de estágio tem um conhecimento profundo das áreas de linguística e de literatura, por exemplo, até mesmo por uma questão de afinidade, além de ser um tempo muito curto para que tudo seja discutido. Esse trabalho deveria ser feito com o professor da área, mas acontece que o professor da área de lingüística e da área de literatura, talvez, por uma questão de carência em sua formação, acaba sendo o professor apenas da disciplina e não trabalha com o pedagógico. A professora de estágio trabalhou com a prática pedagógica, trabalhou com o estágio, mas eu acho que falta, de fato, a inter-relação [...] A própria segregação de áreas acaba sendo um problema porque já pressupõe essas afinidades e eu acho que não deveria ser assim. Todos ali, professores doutores de Linguística, Literatura e Educação são professores primeiro de Língua portuguesa. Praquê serve toda a teoria? Parece que fica a cargo somente do professor de Estágio saber como levar aquela teoria para sala de aula [...] Eu penso que a cada disciplina deveria ter incutido a prática pedagógica [...] Pensar a teoria e depois pensar como essa teoria que foi ensinada pode ser levada para a prática [...] para fazer sentido pra gente [...] Sempre me perguntei o porquê de muitas disciplinas [...] Talvez se o professor fizesse esse trabalho de mostrar a praticidade e a utilidades dela a nossa formação seria mais consolidada e a gente conseguiria ver o sentido de tudo isso. A gente acaba tendo que lidar com esse problema mais tarde porque aprendemos de forma superficial. (Determinação)

Ao analisarmos esses depoimentos percebemos que, a todo tempo, os alunos, colaboradores da pesquisa, demonstram a procura de sentidos para a sua formação e propõem novas formas de se pensar esse processo a partir de suas próprias necessidades, das lacunas que são percebidas ao longo desse percurso e dos desafios que são postos para o Componente de Estágio, uma vez que "o professor de estágio trabalha sozinho, como se o estágio fosse outro curso e não outro componente". A falta de conexão entre os saberes aprendidos nas áreas apresentadas como específicas e os saberes pedagógicos concebidos no Componente de Estágio torna cada vez mais deficiente o processo formativo.A consequência disso vem apresentada nos seguintes excertos: "Sempre me perguntei o porquê de muitas disciplinas [...] Talvez se o professor fizesse esse trabalho de mostrar a praticidade e a utilidade delas a nossa formação seria mais consolidada e a gente conseguiria ver o sentido de 
tudo isso". Observamos que os saberes do curso não têm atribuído sentido à formação desse graduando, apenas tem se estabelecido como uma carga teórica exorbitante que não apresenta utilidade para a sua prática, uma vez que se estabelece de maneira descontextualizada.

Tardif (2008) salienta que muitas concepções teóricas aportadas no processo de formação de professores podem ter sido concebidas sem relação ao ensino e fora do contexto da ação docente, o que compromete a apropriação desses conhecimentos no momento de atuação efetiva na sala de aula.

Nesse sentido, é importante entender o espaço da teoria e da prática no processo formativo, sendo estes elementos que devem caminhar juntos; um não deve ser compreendido como a consequência do outro, devem estabelecer formas de articulação que expressem posições políticopedagógicas significativas para o processo de ensino-aprendizagem. Pimentel (2014) salienta que, é necessário que os conhecimentos teóricos tenham sentido e significado para que se possa perceber a relação entre a teoria e as ações cotidianas. Desta forma, também deveriam ser incluídas nos currículos dos cursos de formação de professores o estudo de situações problema, práticas reais, assim, o que se aprende nos cursos de formação inicial de professores não seriam apenas estereótipos técnicos, mas o saber sobre porque certas ações são realizadas e quando se torna necessário mudar a estratégia (IMBERNÓN, 2011).

Não se trata, pois, de aprender um ofício no qual predominam estereótipos técnicos, e sim de apreender os fundamentos de uma profissão, o que significa saber por que se realizam determinadas ações ou se adotam algumas atitudes concretas, e quando e por que será necessário fazê-lo de outro modo (IMBERNÓN, 2011, p. 6768).

Imbernón (2011) pontua ainda que, a profissão docente não pode mais beber na fonte da mera transmissão dos conhecimentos acadêmicos, assim como não deve ensinar apenas o básico e reproduzir o conhecimento dominante. $\mathrm{O}$ autor salienta que se os seres humanos se tornaram mais complexos, a profissão docente também deverá se tornar. Este é o processo evolutivo que não pode ser freado. Contudo, como é possível que se tenha esta 
concepção uma vez que o processo formativo do professor é fragmentado e demasiadamente teórico?

Tardif (2008) propõe que, nos cursos de formação de professores, os alunos sejam reconhecidos como sujeitos do conhecimento, que não sejam limitados a receber conhecimentos disciplinares e informações procedimentais, que se realize um trabalho no qual se abracem as expectativas cognitivas, sociais e afetivas, ou seja, a subjetividade. O autor aponta, ainda, que "o principal desafio para a formação de professores, nos próximos anos será o de abrir um espaço maior para os conhecimentos práticos dentro do próprio currículo" (TARDIF, 2008, p. 241).

\section{Considerações finais}

Entendendo que esse trabalho se efetiva como um processo e não apenas como um produto, a pesquisa continua, uma vez que as abordagens propostas no decorrer dessa discussão não esgotam as possibilidades de estudos em torno de uma formação inicial analisada sob a perspectiva autobiográfica. Estão imbricadas nessa temática questões inúmeras, que vão desde a complexidade da formação inicial à investigação das subjetividades dos sujeitos em formação. Assim, percebemos que esse estudo se estabelece como um processo rizomático (DELEUZE; GUATARI, 1995), perpassado por diversas conexões, ramificações e possibilidades, superando a certeza de que não existem verdades prontas, acabadas e absolutas.

Ao longo desse trabalho, às nossas palavras se juntaram muitas outras trazidas pelos (as) estudantes que nos ajudaram a compreender melhor a temática escolhida, pois, a partir das análises dos dados essa pesquisa foi tomando rumos jamais imaginados inicialmente. Descortinar contextos, histórias e memórias através das narrativas de formação frente a um projeto de "abordagem experencial" (JOSSO, 2002) se efetivou como um trabalho minucioso que necessitou do olhar e da escuta sensível das pesquisadoras.

Pudemos perceber, no diálogo com as narrativas dos (as) estudantes, o quanto o curso ainda está atrelado aos princípios da racionalidade técnica. Esse entendimento nos moveu a investigar o lugar da reflexão nesse contexto conteudista, entendendo-o como forma de romper com o paradigma da racionalidade técnica e propor uma produção de conhecimento baseada numa perspectiva crítico-reflexiva. 
Ao retomarem as suas histórias de formação pessoal, os (as) estagiários (as) puderam reconstruir as suas experiências formativas entendendo as contribuições destas para a construção de suas aprendizagens. Isso interferiu diretamente nos modos de agir, pensar e sentir a partir da reflexão que fizeram sobre sua própria formação.

Ao pensarmos na formação do professor crítico-reflexivo reforçamos o entendimento do Estágio Supervisionado como um espaço de pesquisa-investigação. Assim sendo, concluímos, nesse contexto, que as experiências reflexivas e investigativas, desenvolvidas no Estágio Supervisionado, possibilitam uma formação profissional docente com um maior comprometimento com o contexto educacional, no qual o futuro professor se insere como um crítico e um questionador.

Por fim, seguimos confiantes que as reflexões aqui explanadas possam contribuir para um (re)pensar dos currículos dos Cursos de Letras e da postura dos professores universitários. Confiamos também que essa pesquisa demonstre que o trabalho com a perspectiva autobiográfica tem dado certo e que é preciso valorizar as subjetividades dos (as) estudantes no processo de formação. Acreditamos que os estudos que se debruçam sobre as práticas educativas podem ajudar na compreensão do que está sendo feito e visualizar o que ainda precisa ser feito.

\section{Referências}

BARREIRO, I. M. de F.; GEBRAN, R. A. Prática de ensino e estágio supervisionado na formação de professores. São Paulo: Avercamp, 2006.

BEHRENS, Marilda. Formação continuada dos professores e a prática pedagógica. Curitiba: Champagnat, 1996.

BRASIL, Ministério da Educação. Proposta de diretrizes para a formação inicial de professores da educação básica, em cursos de nível superior. 2000.

COSTA, J. da S. Docência no ensino superior: professor aulista ou professor pesquisador? Caderno Discente do Instituto Superior de Educação. Aparecida de Goiânia. Ano 2, n.2, 2008.

FREIRE, P. Pedagogia do Oprimido. 11. ed. Rio de Janeiro: PAZ E TERRA, 1970.

IMBERNÓN, F. Formação docente e profissional - forma-se para a mudança e a incerteza. 9ạed. São Paulo: Cortez, 2011 - Coleção questões da nossa época; v. 14 
AS NARRATIVAS DE SI E AS TRAVESSIAS CONSTRUIDAS NO PROCESSO DA COMPLEXIDADE DA FORMAÇÂOO INICIAL

PEREIRA, P. S. A concepção de prática na visão de licenciandos de Matemática. 2005. Tese (Doutorado em Educação Matemática) Universidade de Estadual Paulista, Rio Claro.

PIMENTA, Selma Garrido (org.). Saberes Pedagógicos e Atividade Docente. 4.ed. São Paulo: Cortez, 2005.

PIMENTA, S. G.; LIMA, M. S. L. Estágio e Docência. 6ạ Ed. São Paulo: Cortez, 2011.

NÓVOA, António. Os professores e sua formação. Lisboa, Portugal: Dom Quixote, 1992

SILVA, J. Q. G.; MATENCIO, M. L. M. Movimentos do sujeito na produção de sentidos: subjetivação e objetivação. Revista Scripta, v. 8, n. 16, 2005. p. 71-78.

TARDIF, Maurice. Saberes docentes e formação profissional. Petrópolis: Editora Vozes, 2008.

ZABALZA, M. O Ensino Universitário: seu cenário e seus protagonistas. Porto Alegre: ARTMED, 2004.

Recebido em 29 de abril de 2019.

Aceito em 30 de maio de 2019. 